\title{
Image Digitization of Colorimetric Detection of Acephate Based on Its Complexation with Citrate-Capped Gold Nanoparticles
}

\author{
Mohd Junaedy Osman $\mathbb{D}^{1},{ }^{1}$ Wan Md Zin Wan Yunus $\mathbb{D}^{2},{ }^{2}$ Keat Khim Ong $\mathbb{D},{ }^{1,3}$ \\ Buong Woei Chieng $\mathbb{D},{ }^{3}$ Noor Azilah Mohd Kassim $\mathbb{D}^{1,3}$ Siti Aminah Mohd Noor $\mathbb{D}^{1},{ }^{1}$ \\ Victor Feizal Knight $\mathbb{D},{ }^{3}$ Jahwarhar Izuan Abd Rashid $\mathbb{D},{ }^{1}$ and Chin Chuang Teoh $\mathbb{D}^{4}$ \\ ${ }^{1}$ Centre for Defence Foundation Studies, Universiti Pertahanan Nasional Malaysia, Kem Sg Besi, Kuala Lumpur 57000, Malaysia \\ ${ }^{2}$ Centre for Tropicalisation, Universiti Pertahanan Nasional Malaysia, Kem Sg Besi, Kuala Lumpur 57000, Malaysia \\ ${ }^{3}$ Centre for Chemical Defence, Universiti Pertahanan Nasional Malaysia, Kem Sg Besi, Kuala Lumpur 57000, Malaysia \\ ${ }^{4}$ Engineering Research Centre, MARDI Headquarter Serdang, Serdang 43400, Selangor, Malaysia
}

Correspondence should be addressed to Wan Md Zin Wan Yunus; wanmdzin@upnm.edu.my

Received 7 September 2020; Revised 6 November 2020; Accepted 16 November 2020; Published 30 November 2020

Academic Editor: Vinod Kumar Tiwari

Copyright $\odot 2020$ Mohd Junaedy Osman et al. This is an open access article distributed under the Creative Commons Attribution License, which permits unrestricted use, distribution, and reproduction in any medium, provided the original work is properly cited.

\begin{abstract}
Acephate (Ac), an organophosphate (OP) insecticide, is very harmful to human and the environment. Conventional techniques of detection are sensitive and selective but relatively time-consuming, expensive, and require trained personnel. This paper describes the use of an image processing technique to digitize the red values (RVs) of the colour image of Ac-capped gold nanoparticles (AcCit-AuNPs) complex captured using a digital microscope to improve the detection accuracy and precision. The formation of the suspension was characterised using laser test, ultraviolet-visible spectrophotometer (UV-Vis), high-resolution transmission electron microscope (HRTEM), and Fourier Transform infrared spectroscope (FTIR). The linear regression analysis revealed that the detection sensitivity improved as the smaller gold nanoparticles were used. For quantitative measurement using image processing, a good linear relationship $\left(R^{2}=0.9905\right.$ and 0.9924$)$ for Cit-HAuNPs and Cit-MAuNPs, respectively, between the concentration of $A c$ and average red values was obtained in the range of $0-8 \mathrm{mM}$. The limit of detection (LOD) for Ac was found to be $0.3 \mathrm{mM}$ and $0.4 \mathrm{mM}$ for Cit-MAuNPs and Cit-HAuNPs, respectively.
\end{abstract}

\section{Introduction}

Conventional techniques that are commonly used for the detection of organophosphates (OPs) include high-performance liquid chromatography (HPLC) [1], mass spectrometry [2-4], enzyme-linked immunosorbent assay (ELISA) [5], nanoparticle colour complex formation [6], and biosensors based on inhibition of cholinesterase activity $[7,8]$. These methods provided a high selectivity of the detection, but they are relatively time-consuming, expensive, and require trained personnel $[2,9,10]^{\circ}$ Therefore, discovery of a simple, rapid, and less expensive but reliable, sensitive and selective method for the analysis of OPs, especially for onsite detections, is desirable, especially for quick data gathering in OPs poisoning management.
Interaction of OPs and citrate ion-gold nanoparticle(Cit-AuNP-) based colorimetric assays are very attractive for rapid detection due to the ease of procedures and visualization of results $[11,12]$. The colour change of red CitAuNPs suspension to steel-purple complex upon aggregation of the particles has been used as the basis of the colorimetric OPs sensing [13].

Acephate (Ac) (O,S-dimethyl acetylphosphoramidothioate), an organophosphate insecticide [14], inhibits acetylcholinesterase enzyme (AChE) $[15,16]$. In addition, this compound can be decomposed into methamidophos, which is even more toxic than the original compound [17], thus posing more harm to insects, birds, mammals, and plants. Since Ac is a hydrophilic compound, it is poorly absorbed by soils. Thus, there was high possibility for this 
compound to become water contaminant [14]. It has been reported that prolonged exposure to Ac led to significant increase of genotoxicity and cardiotoxicity activities $[18,19]$.

Figure 1 shows the structural formula of Ac. Generally, OPs undergo SN2 nucleophilic substitution at phosphorus centre [20] via two different pathways (addition-elimination and direct-displacement) [20]. Ac was expected to undergo this substitution at $\mathrm{P}-\mathrm{N}$ bond.

Citrate-capped gold nanoparticles (Cit-AuNPs) are widely used materials in colorimetric detection methods because of the colour stability, excellent biocompatibility, and convenience for surface functionalization. In addition, Cit-AuNPs have high tendency to display a distinct colour change that makes Cit-AuNPs ideal to be applied for sensing application.

Interestingly, Cit-AuNPs were prepared via various approaches that include chemical, sonochemical, and photochemical paths [21]. The simplest chemical route to prepare this material was by reduction of chloroauric acid $\left(\mathrm{HAuCl}_{4}\right)$ using reducing agents such as trisodium citrate, block copolymer, organic acids, or amine compounds $[22,23]$. This method produces particles with a diameter size of below than $50 \mathrm{~nm}$ which was favourable for surface functionalization due to their large surface area. The colour change of Cit-AuNPs was very sensitive to the particle size, capping agent, and aggregation state of Cit-AuNPs [24-26]. Cit-AuNPs was usually prepared via thermal heating in which chloroauric acid is reduced by trisodium citrate. The product was a diamond red suspension. Recently, microwave radiation heating has been found to be an efficient heating technique to produce much finer Cit-AuNPs $[27,28]$.

In this preliminary study, the sensitivity of the unmodified Cit-AuNPs synthesized via both thermal heating and microwave radiation, for colorimetric detection of Ac, was compared. The detection was based on the colour change produced from the reaction of Ac and Cit-AuNPs that results distinct colour change from diamond red to dark purple for Ac-Cit-AuNPs complex. To improve its accuracy and precision, the colours of the solutions were photographed and digitised using ImageJ software to obtain their red values (RVs).

\section{Materials and Methods}

2.1. Materials. Chloroauric acid trihydrate $\left(\mathrm{HAuCl}_{4} \cdot 3 \mathrm{H}_{2} \mathrm{O}\right.$; $>49 \% \mathrm{Au}$ basis) $(\mathrm{Au})$ and acephate $\left(\left(\mathrm{C}_{4} \mathrm{H}_{10} \mathrm{NO}_{3} \mathrm{PS}\right)(\mathrm{Ac})\right)$ of Pestanal analytical grade were purchased from SigmaAldrich, USA. Trisodium citrate dihydrate $\left(\mathrm{C}_{6} \mathrm{H}_{5} \mathrm{Na}_{3} \mathrm{O}_{7} .2 \mathrm{H}_{2} \mathrm{O}\right)$ (Na-Cit) was purchased from Merck $\mathrm{KGaA}$, Germany. All other reagents were of analytical grade. All dilutions were carried out using MilliQ water of $18.2 \mathrm{M} \Omega$ $\mathrm{cm}$.

\subsubsection{Synthesis of Cit-AuNPs via Thermal Heating Technique.} Cit-AuNPs were synthesized based on the reported procedure $[27,29]$ with some modifications. The details of the procedure used is as follows: $100 \mathrm{~mL}$ of $0.25 \mathrm{mM}$ of $\mathrm{Au}$

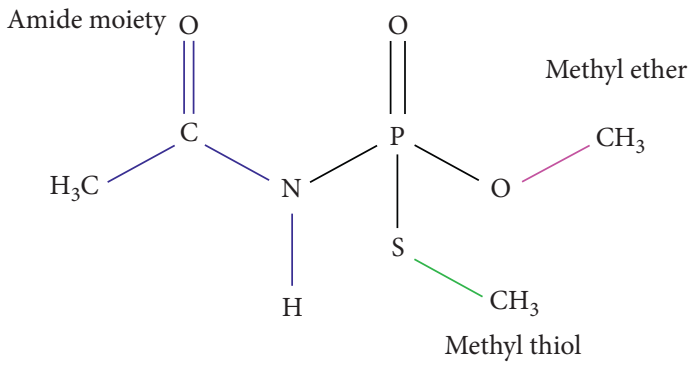

Figure 1: Ac structure with its characteristic functional groups.

solution was heated under reflux with constant stirring of $300 \mathrm{rpm}$ to boil and followed by rapid addition of $2 \mathrm{~mL}$ $34 \mathrm{mM} \mathrm{Na}$-Cit. The reaction mixture was then further boiled under the stirring for 20 minutes. The suspensions were then cooled down to room temperature and stored in dark bottle at $5.0 \pm 0.5^{\circ} \mathrm{C}$. This suspension was labelled as Cit-HAuNPs.

2.1.2. Synthesis of Cit-AuNPs via Microwave Radiation Technique. The same amounts of the reagents used for the heating technique, i.e., $100 \mathrm{~mL}$ of $0.25 \mathrm{mM}$ of $\mathrm{Au}$ solution and $2 \mathrm{~mL}$ of $34 \mathrm{mM} \mathrm{Na}$-Cit were mixed and placed in a microwave oven (Panasonic NN-CS599S output $1000 \mathrm{w}$ Serial number 5G71230007). The mixture was irradiated for $10 \mathrm{~min}$ at $300 \mathrm{w}$. The produced suspension was cooled down to room temperature, stored in dark bottle at $5.0 \pm 0.5^{\circ} \mathrm{C}$, and labelled as Cit-MAuNPs.

2.1.3. Colorimetric Detection of Ac Using Cit-AuNPs. Typically, triplicate samples of each $900 \mu \mathrm{L}$ Cit-HAuNPs or $900 \mu \mathrm{L}$ Cit-MAuNPs were reacted with $100 \mu \mathrm{L}$ of Ac of different concentrations $\left(1.00 \times 10^{-5} \mathrm{mM}, 1.00 \times 10^{-3} \mathrm{mM}\right.$, $0.40 \mathrm{mM}, 1.00 \mathrm{mM}, 4.00 \mathrm{mM}$, or $8.00 \mathrm{mM}$ ) in a glass vial. The colours of the top view of Ac-Cit-HAuNPs or Ac-Cit-MAuNPs suspensions produced were photographed using a portable digital microscope. Considering that, for Ac detection, the colour changes from red suspension to dark purple complex, and it is best to refer to the changes in red values (RVs) compared to referring to green and blue colour channel of the digitized images. The RVs of all images were digitized using ImageJ software and processed using a regression. The maximum readings of absorbance of each Ac-Cit-HAuNPs and AcCit-MAuNPs suspension were measured by ultraviolet-visible spectrophotometry. The particle distribution was studied by high resolution transmission electron microscopy. Formation and interaction of bonding between Ac and Cit-AuNPs were studied by Fourier transform infrared spectroscopy.

\section{Characterizations}

3.1. Laser Test. Laser test was performed using a Logitech laser pointer with wavelength ranged from $640 \mathrm{~nm}$ to $660 \mathrm{~nm}$.

3.2. High Resolution Transmission Electron Microscopy (HRTEM). HRTEM analysis was performed using a JEOL JEM 2100F HRTEM. Samples of Cit-AuNPs were dropped 
on the viewing grids and left overnight to dry. The HRTEM image of each sample was obtained, and the average diameter of gold particles, size distribution and standard distribution was manually calculated based on the average of 100 gold particles in the TEM images.

3.3. Ultraviolet-Visible (UV-Vis) Spectroscopy. UV-Vis analysis was performed using a Genesys $6 \mathrm{UV}$-Vis spectrophotometer at a scanning rate of $1 \mathrm{~nm} / \mathrm{sec}$ from $200 \mathrm{~nm}$ to $1000 \mathrm{~nm}$. Absorbance versus wavelength data was recorded for each sample.

3.4. Fourier Transform Infrared (FTIR) Spectroscopy. FTIR analysis was performed using a Perkin Elmer Spectrum 100 equipped with Attenuated Total Reflection (ATR) accessory. The instrument was set at resolution $4.0 \mathrm{~cm}^{-1}$ and scanning rate of $4 \mathrm{~cm}^{-1} / \mathrm{sec}$. The background was collected by use of air before each scan.

3.5. Image Processing. Image processing was carried out using Image software (Oracle, USA) to obtain the image RVs of the respective samples.

\section{Results and Discussion}

4.1. Synthesis of Cit-AuNPs. In this study, Cit-AuNPs were synthesized via chemical reduction of $\mathrm{Au}^{3+}$ ions to $\mathrm{Au}$ particles using $\mathrm{Na}-\mathrm{Cit}$ as the reducing agent. Previous study has reported that there are several steps involved in the formation of Cit-AuNPs [30]. The formation of Cit-AuNPs was indicated by the formation of a diamond red suspension [31-33] and confirmed by a laser test whereby surface plasmon resonance (SPR) phenomenon was observed as shown by the appearance of a laser beam through the suspension (Figures 2(a) and 2(b)) [34]. The SPR phenomenon arose from collective oscillation of the conduction band of electron in Cit-AuNPs [35].

Figure 3 shows absorption spectra of the $\mathrm{HAuCl}_{4}$ solution, Cit-HAuNPs, and Cit-MAuNPs suspension. The strong absorption peak at $210 \mathrm{~nm}$ observed for $\mathrm{HAuCl}_{4}$ aqueous solution spectrum is due to ligand to metal charge transfer (LMCT) of $\mathrm{AuCl}_{4}^{-}$ions. [36-39] The absorbances of Cit-HAuNPs and Cit-MAuNPs at $526 \mathrm{~nm}$ are 0.1052 and 0.0871 , resulting from SPR phenomenon $[40,41]$ of CitHAuNPs and Cit-MAuNPs, respectively. The difference of the absorbance of the Cit-HAuNPs and of the Cit-MAuNPs is probably due to dissimilarity of size of the nanoparticles $[36,42,43]$.

Figure 4 shows HRTEM images of Cit-HAuNPs and CitMAuNPs. The images show that Cit-AuNPs are mostly in spherical shape. A well-defined interparticle boundary for both Cit-HAuNPs and Cit-MAuNPs suggests that the particles are well separated. In addition, the difference in size was clearly observed from the images. The size distribution histograms of the Cit-AuNPs are shown in Figure 5. From the histograms, the measured particle size of both CitHAuNPs and Cit-MAuNPs were ranging between 5 to
$30 \mathrm{~nm}$ and 2 to $18 \mathrm{~nm}$, respectively. The difference in size might be because the uniform reaction temperature achieved throughout the microwave irradiated technique in comparison with that of the thermal heating technique $[28,44,45]$.

Figure 6(a) presents FTIR spectra of the Cit-HAuNPs suspension and $\mathrm{Na}$-Cit solution. The presence of broad peak at above $3000 \mathrm{~cm}^{-1}$ suggests $\mathrm{O}-\mathrm{H}$ stretching indicating the presence of water. Peaks at $1585 \mathrm{~cm}^{-1}$ and $1395 \mathrm{~cm}^{-1}$ show the existence of carboxylate asymmetric stretching $\left(\mathrm{COO}^{-}\right.$ As) and carboxylate symmetric stretching $\left(\mathrm{COO}^{-} \mathrm{S}\right)$, respectively. Peaks at $1280 \mathrm{~cm}^{-1}$ and $1075 \mathrm{~cm}^{-1}$ are due to C-O stretching. Meanwhile, peak at $731 \mathrm{~cm}^{-1}$ indicates carboxylate bending $\left(\mathrm{COO}^{-}\right.$bending). The shifts of the $\mathrm{COO}^{-}$As peak to higher wavenumber and the peak $\mathrm{COO}^{-} \mathrm{S}$ to the lower wavenumber, compared to those of the $\mathrm{Na}$-Cit, suggest that the binding of Cit-HAuNPs is through unidentate coordination of citrate ions anchoring only one oxygen atom as shown in Figure 6(b) [46].

4.2. Colorimetric Detection of Ac. Figure 7 displays the colour images of Ac-Cit-HAuNPs and Ac-Cit-MAuNPs suspensions formed in the presence of different concentrations of Ac. The diamond red colour of the Cit-AuNPs suspensions changed to dark purple as the concentration of Ac increased. Addition of Ac caused the Ac-Cit-AuNPs to have a "red shift" from $527 \mathrm{~nm}$ (Cit-AuNPs) to higher wavelength (Ac-Cit-AuNPs complex) as shown by the UV-Vis spectrum, due to particle aggregation of the complex. Figure 8 shows the absorbance intensity at $527 \mathrm{~nm}$ decreased as the concentration of Ac increased. This phenomenon was explained by the formation of larger cluster due to aggregation of particles [31, 35]. Furthermore, a new absorbance peak at $650-750 \mathrm{~nm}$ which indicated the particle aggregation, both for Ac-CitHAuNPs and Ac-Cit-MAuNPs [47], was observed.

TEM images (Figure 9) represent aggregation of nanoparticles after detection of Ac for Cit-HAuNPs and CitMAuNPs. Initially, nanoparticles were separated due to repulsion from the citrate ion anchored to Au. Ac interacts at the anion through SN2-type mechanism at phosphate centre, thus leading to aggregation of particles in both cases.

The proposed chemical equation for reaction of Ac and Cit-AuNPs is as follows:

$$
\begin{aligned}
& \mathrm{C}_{4} \mathrm{H}_{10} \mathrm{NO}_{3} \mathrm{PS}+\mathrm{Au}^{0}+\mathrm{C}_{4} \mathrm{H}_{4} \mathrm{O}_{5}^{2-}+\mathrm{H}^{+} \longrightarrow \mathrm{Au}^{0}+\mathrm{C}_{4} \mathrm{H}_{4} \mathrm{O}_{5}^{2-} \\
& +\mathrm{C}_{2} \mathrm{H}_{6} \mathrm{O}_{2} \mathrm{P}^{+} \mathrm{S}+\mathrm{H}_{2} \mathrm{NOC}_{2} \mathrm{H}_{3}
\end{aligned}
$$

Figure 10 shows FTIR spectra of Ac solution and CitHAuNPs and Ac-Cit-HAuNPs complex. A broad intense peak around $3350 \mathrm{~cm}^{-1}$ in Cit-HAuNPs and Ac-CitHAuNPs FTIR spectra belongs to $\mathrm{O}-\mathrm{H}$ stretching from water which was the solvent used in this experiment. All indicative peaks for Cit-HAuNPs are mentioned earlier. Table 1 represents the functional group, and it quantifies wavenumber for Ac $[48,49]$. Ac, with a central phosphorus atom (P), has characteristic phosphoric $(\mathrm{P}=\mathrm{O})$, methyl thiol, methyl ether, 


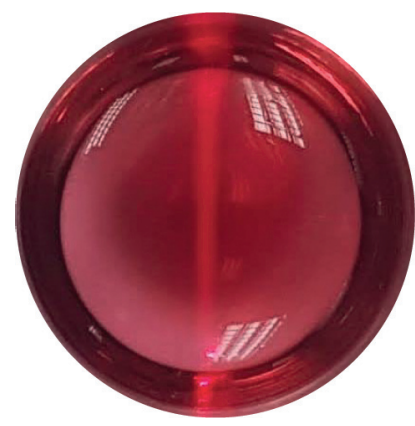

(a)

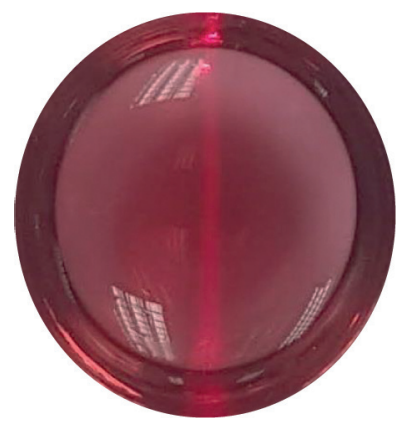

(b)

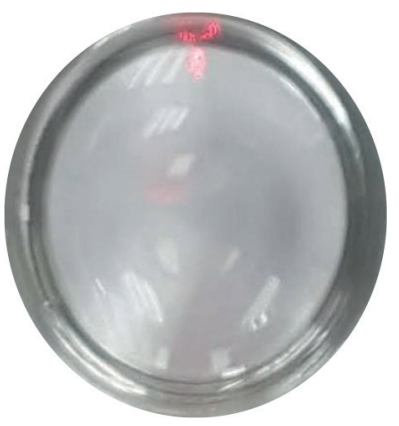

(c)

FIGURE 2: Surface plasmon resonance phenomenon test results for (a) Cit-HAuNPs and (b) Cit-MAuNPs and (c) MilliQ water.

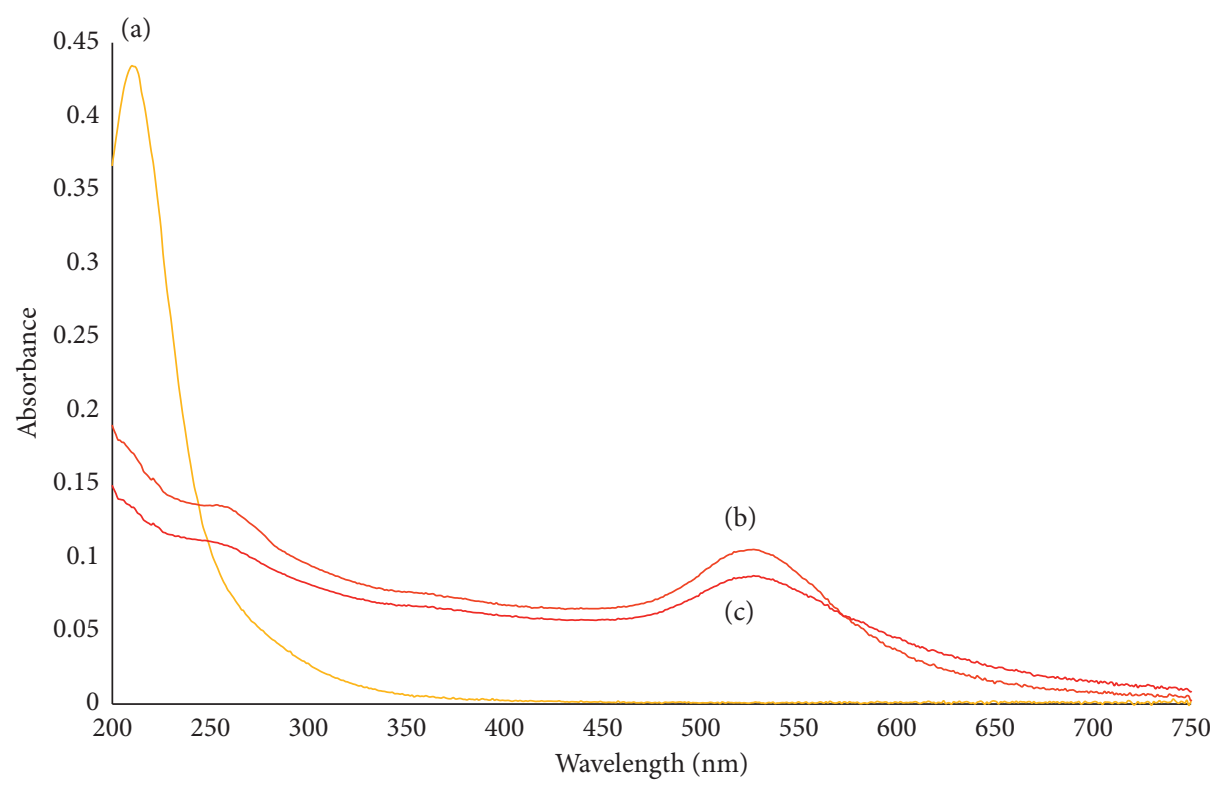

FIGURE 3: UV-Vis absorbance spectra of (a) $\mathrm{HAuCl}_{4}$ solution and suspensions of (b) Cit-HAuNPs and (c) Cit-MAuNPs.

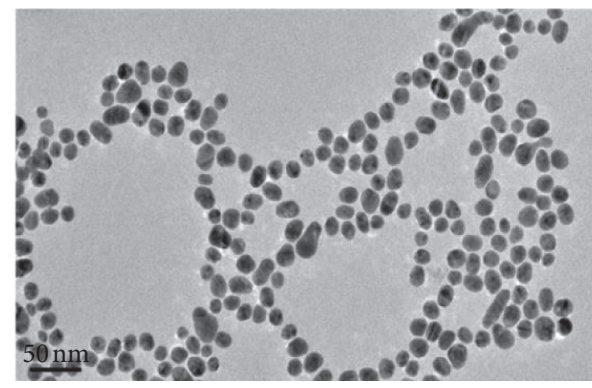

(a)

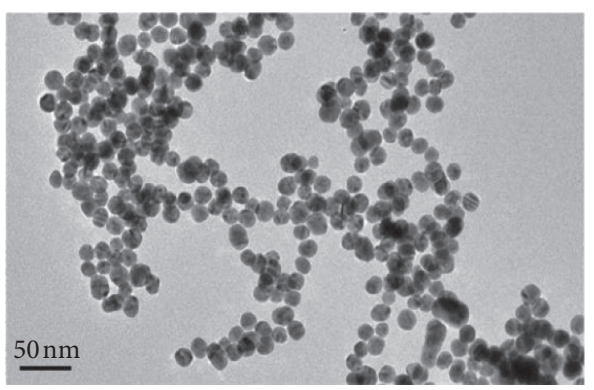

(b)

Figure 4: HRTEM micrographs of (a) Cit-HAuNPs and (b) Cit-MAuNPs at 50000x magnification.

and amide bonds (Figure 10). P-N bond cleavage in Ac is a multistep addition-elimination pathway, and amide is replaced by unidentate citrate ion in Cit-AuNPs according to SN2-type mechanism $[20,46,50]$ in an acidic condition [46] where an unstable intermediate is formed.
Reaction of Ac with Cit-HAuNPs is a nucleophilic substitution. This reaction occurs at phosphorus atom where citrate ion of Cit-HAuNPs replaces the amide and breaks $\mathrm{P}-\mathrm{N}$ bond in the Ac structure [17]. The FTIR spectrum of AcCit-AuNPs shows disappearance of the peak at around 


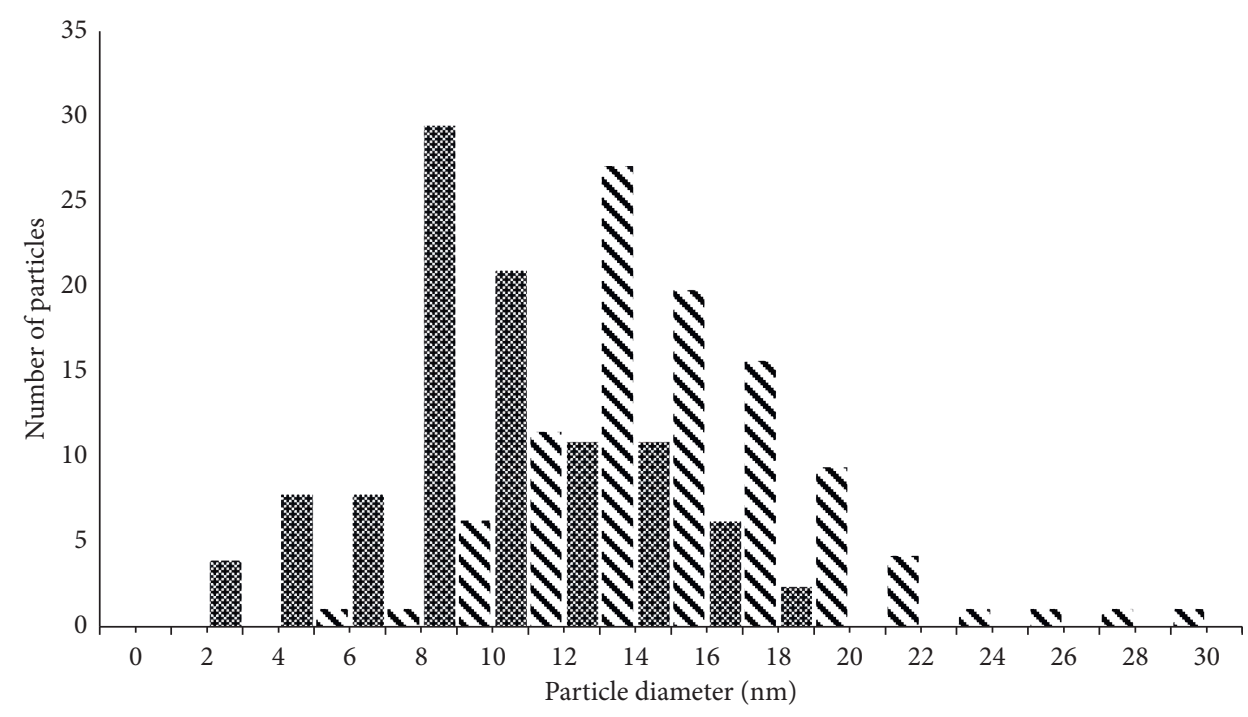

S H-AuNP

M-AuNP

FIgURE 5: Size distribution of Cit-HAuNPs and Cit-MAuNPs.

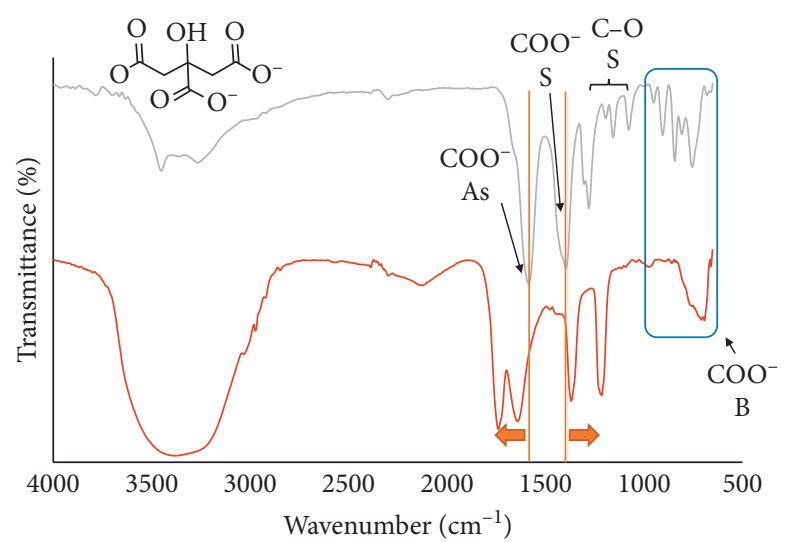

(a)

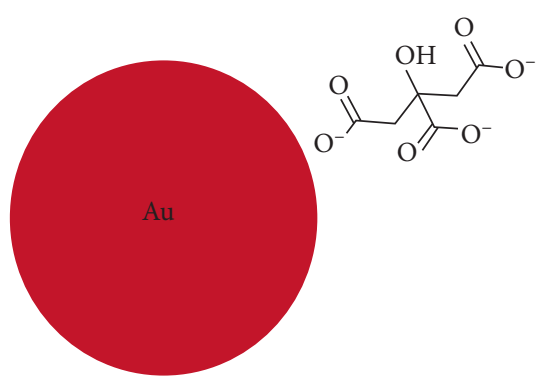

(b)

Figure 6: (a) FTIR spectra of Cit-HAuNPs suspension and Na-Cit solution and (b) proposed schematic of unidentate coordination of the Cit-AuNPs.

$3200 \mathrm{~cm}^{-1}$ (N-H stretching) and the reduction of the peak intensity around $1230 \mathrm{~cm}^{-1}(\mathrm{P}=\mathrm{O}$ and $\mathrm{C}-\mathrm{N}$ stretching) supporting the suggestion that there is a replacement of the amide group by citrate ion of Cit-HAuNPs. In addition, the intensity of $\mathrm{COO}^{-}$stretching peak around $1395 \mathrm{~cm}^{-1}$ is also reduced after the reaction. Reaction of Ac and Cit-HAuNPs hinders the $\mathrm{COO}^{-}$stretching structure, thus reducing the intensity of its FTIR peak [51]. Figure 11 proposed the schematic of nucleophilic substitution mentioned with assumption that all negatively charged citrate ions were completely reacted with Ac.

4.3. Image Processing. Colour change of Cit-AuNPs was associated with the degree of aggregation of Cit-AuNPs. RVs were attained by capturing the image of the Ac-Cit-
AuNPs complex and digitizing the red colour of the captured images by ImageJ software. The RVs can effectively represent the degree of aggregation for Ac-CitAuNPs complex [52]. As the concentration of Ac was increased, higher degree of aggregation was expected and colour change from red (Cit-AuNPs) to purple (Ac-CitAuNPs) was enhanced. Thus, the RVs were reduced. Table 2 shows the average of RVs of Ac-Cit-HAuNPs and Ac-CitMAuNPs. The average values were used in developing linear regression model for each type of particles and found to be fitted with the following equations: $Y=138.6-9.875 X$ for Cit-HAuNPs and $Y=130.7-10.66 X$ for Cit-MAuNPs (Figure 12), where $Y$ is the average RVs and $X$ is the concentration of Ac. The slopes of the linear equations represent the sensitivity of both Cit-AuNPs to detect Ac [53-56]. The steeper slope of the Cit-MAuNPs regression 


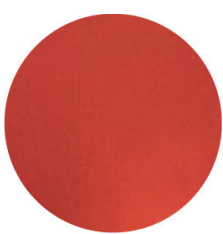

(a)

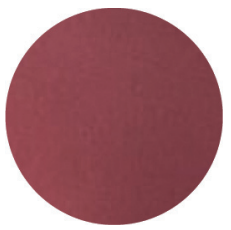

(a)

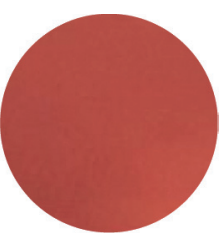

(b)

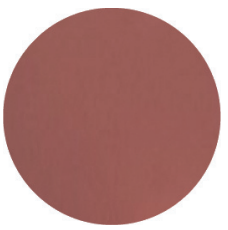

(b)

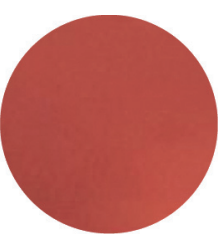

(c)

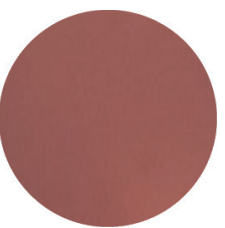

(c)

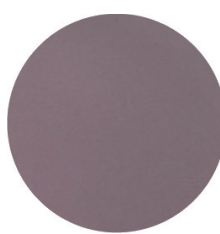

(d)

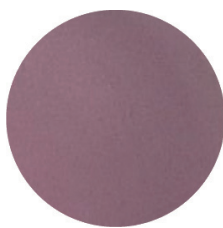

(d)

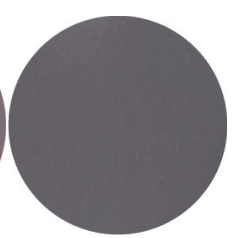

(e)

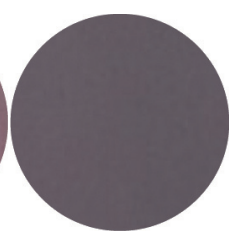

(e)

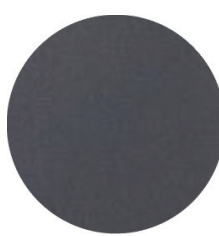

(f)

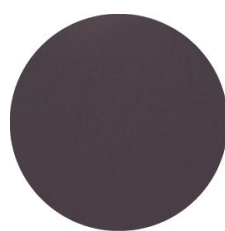

(f)

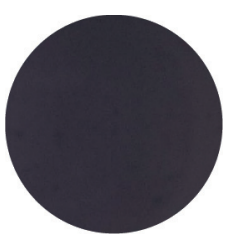

(g)

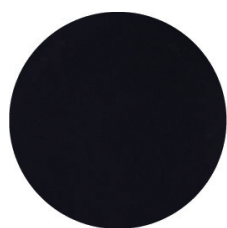

(g)

Figure 7: Colour images for (i) Ac-Cit-HAuNPs and (ii) Ac-Cit-MAuNPs complexes in the presence of different concentrations of Ac ((a) $0.00 \mathrm{mM}$, (b) $1.00 \times 10^{-5} \mathrm{mM}$, (c) $1.00 \times 10^{-3} \mathrm{mM}$, (d) $0.40 \mathrm{mM}$, (e) $1.00 \mathrm{mM}$, (f) $4.00 \mathrm{mM}$, and (g) $8.00 \mathrm{mM}$.

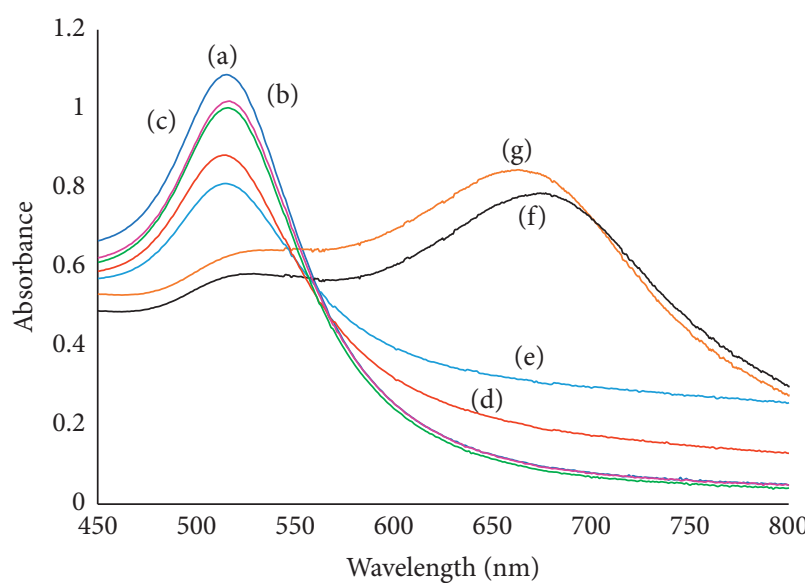

(a)

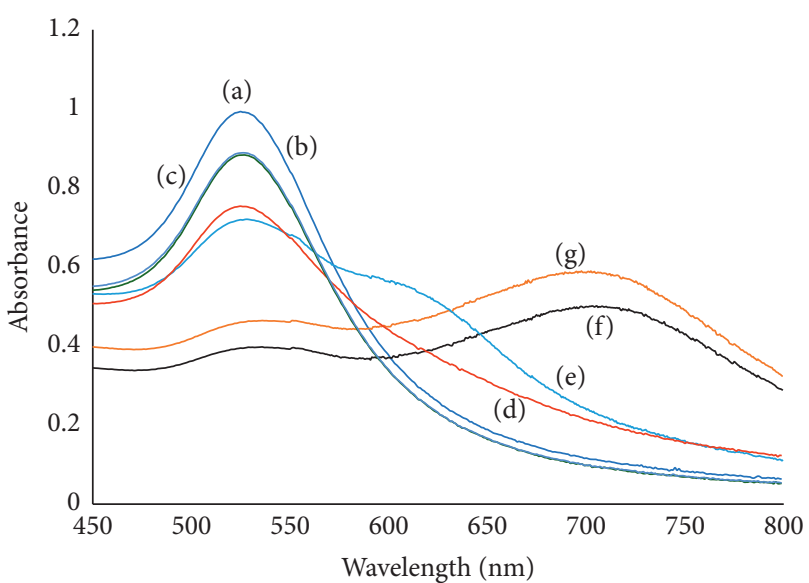

(b)

FIgure 8: UV-Vis spectra of (i) Ac-Cit-HAuNPs and (ii) Ac-Cit-MAuNPs complexes after reacting with various concentrations ((a) $0.00 \mathrm{mM}$, (b) $1.00 \times 10^{-5} \mathrm{mM}$, (c) $1.00 \times 10^{-3} \mathrm{mM}$, (d) $0.40 \mathrm{mM}$, (e) $1.00 \mathrm{mM}$, (f) $4.00 \mathrm{mM}$, and (g) $8.00 \mathrm{mM}$ ) of Ac solutions.

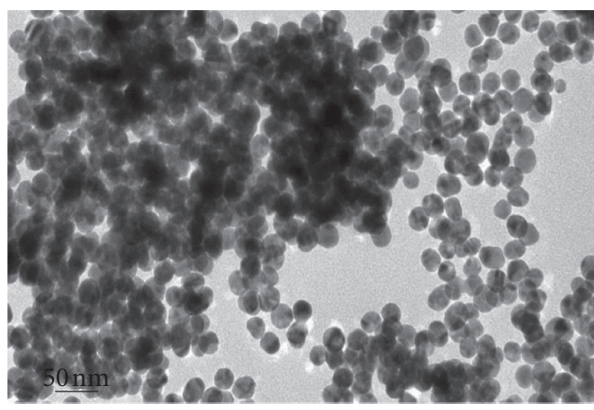

(a)

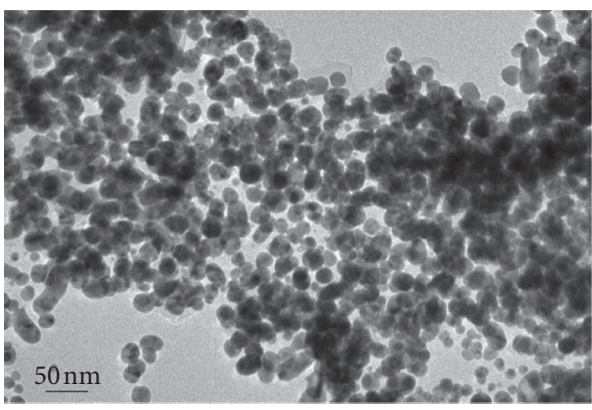

(b)

Figure 9: HRTEM images for (a) Ac-Cit-HAuNPs and (b) Ac-Cit-MAuNPs at 50000x magnification.

compared with that of the Cit-HAuNPs indicates the detection based on Cit-MAuNPs is more sensitive. This shows that the detection sensitivity of the Ac detection improves if smaller Cit-AuNPs are used. This is probably due to the fact that finer nanoparticle size offers larger surface area for the interaction $[57,58]$. The $R^{2}$ value was higher when the 


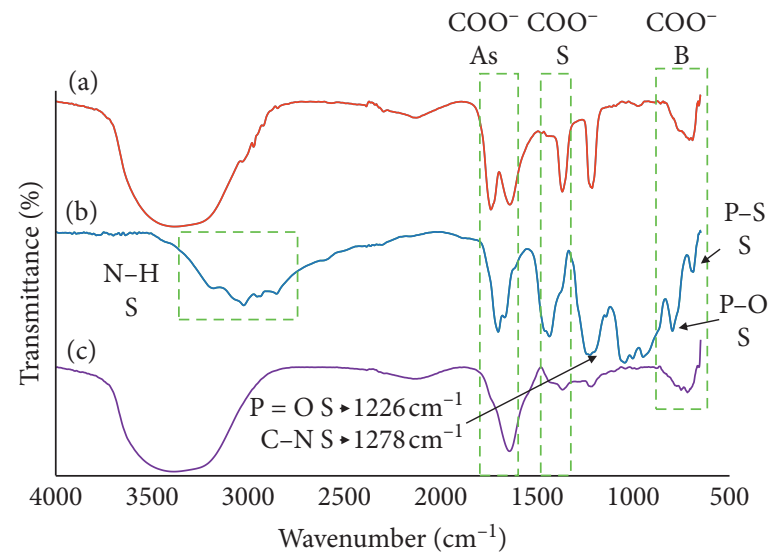

FIgURE 10: FTIR spectra of (a) Cit-HAuNPs, (b) Ac, and (c) Ac-Cit-HAuNPs.

TABLE 1: Indicative FTIR peaks for Ac.

Functional group

$\mathrm{N}-\mathrm{H}$ stretching

$\mathrm{COO}^{-}$As

$\mathrm{COO}^{-} \mathrm{S}$

$\mathrm{P}=\mathrm{O}$ stretching

P-S stretching
Wavenumber $\left(\mathrm{cm}^{-1}\right)$

3200

1585

1395

1226

700

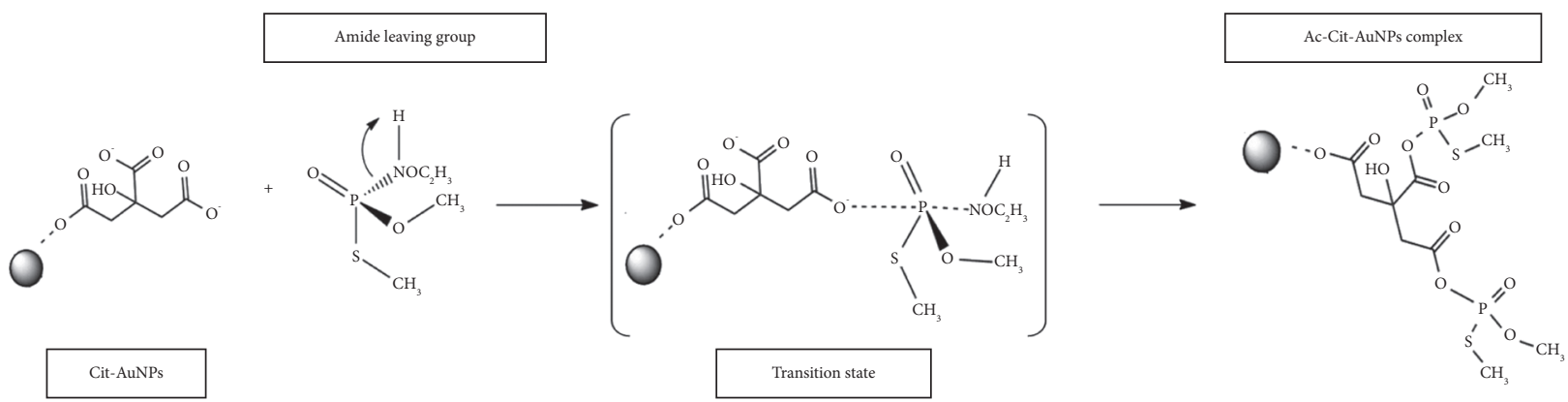

FIGURE 11: SN2 nucleophilic substitution schematic of colorimetric detection of Ac.

TABle 2: Images of Ac-Cit-HAuNP and Ac-Cit-MAuNP complex and their average RVs.

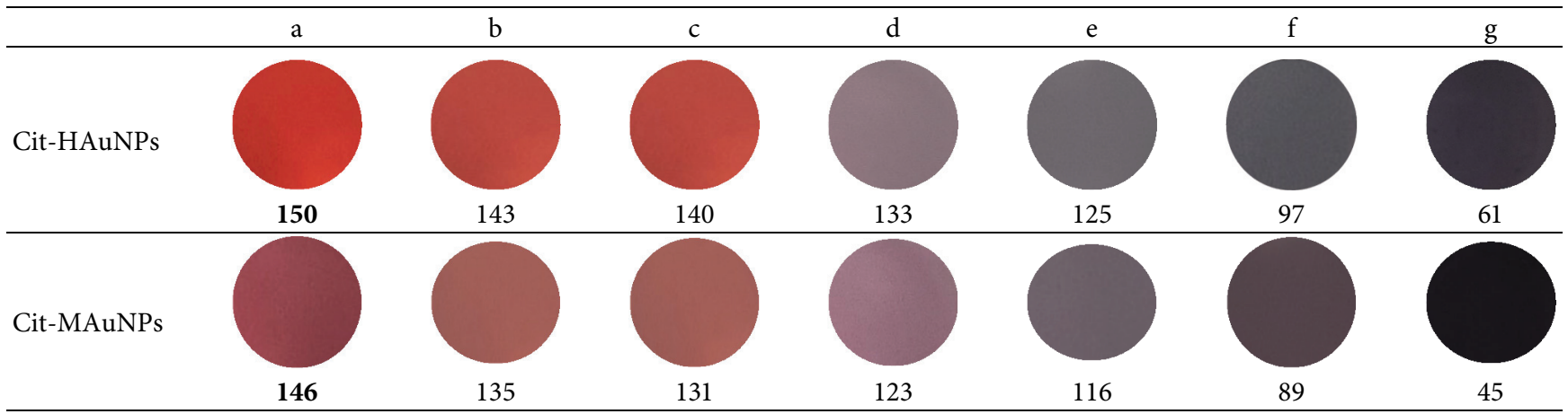

The value for Cit-AuNPs prepared via different procedure. 


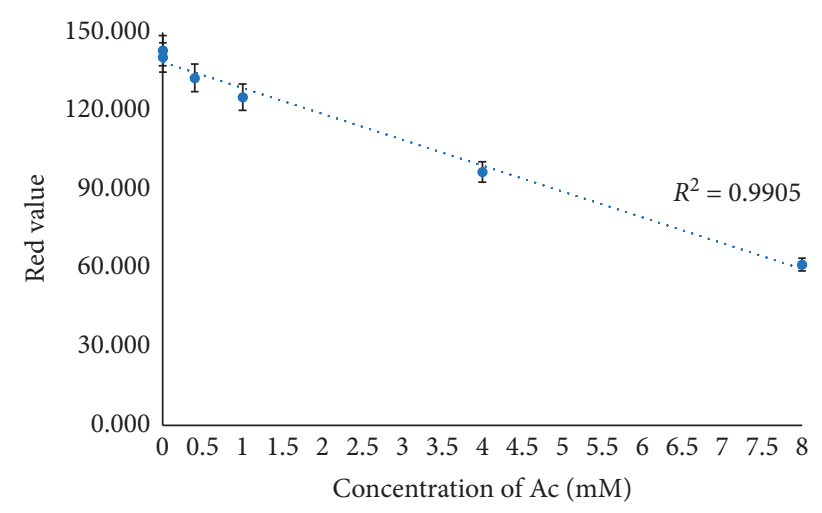

(a)

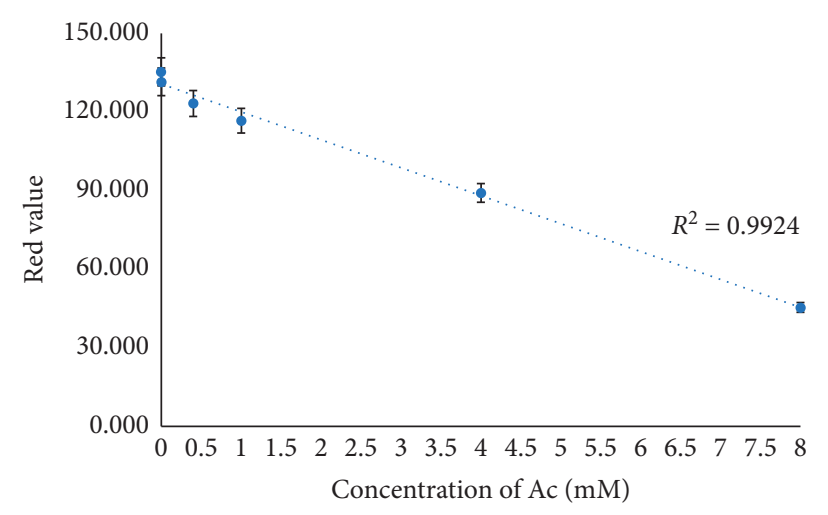

(b)

FIgURE 12: Fitted line plot of RVs vs. concentration for (a) Ac-Cit-HAuNPs and (b) Ac-Cit-MAuNPs complexation.

detection of Ac was conducted using Cit-MAuNPs (0.9924) compared with that of the Cit-HAuNPs (0.9905).

\section{Conclusions}

Cit-AuNPs, prepared through either thermal conventional heating or microwave irradiation, were suitable to be used for colorimetric detection of Ac. UV-Vis and FTIR suggested that SN2 nucleophilic substitution of amide with citrate ion induces nanoparticle aggregation for Ac-Cit-AuNPs responsible for the formation of the purple complex. Finer particles of CitMAuNPs provide slightly more sensitive detection of Ac as shown a bigger slope of regression equation obtained.

\section{Data Availability}

The data used to support the findings of this study are included within the article.

\section{Conflicts of Interest}

The authors declare no conflicts of interest.

\section{Acknowledgments}

This work was supported by the Ministry of Education Malaysia (UPNM/2018/CHEMDEF/ST01) and Universiti Pertahanan Nasional Malaysia by providing the workplace to conduct the project.

\section{References}

[1] C. C. Leandro, P. Hancock, R. J. Fussell, and B. J. Keely, "Comparison of ultra-performance liquid chromatography and high-performance liquid chromatography for the determination of priority pesticides in baby foods by tandem quadrupole mass spectrometry," Journal of Chromatography A, vol. 1103, no. 1, pp. 94-101, 2006.

[2] M. J. Osman, W. M. Z. Wan Yunus, K. K. Ong, and J. Abd Rashid, "Defence science, engineering \& technology recent advances techniques for detection of organophosphates: a review," Journal of Defence Science, Engineering \& Technology, vol. 2, no. 2, pp. 49-70, 2019.
[3] J. Mckenna, E. S. Dhummakupt, T. Connell et al., "Detection of chemical warfare agent simulants and hydrolysis products in biological samples by paper spray mass spectrometry," The Analyst, vol. 142, no. 9, pp. 1442-1451, 2017.

[4] F. Herna, J. V. Sancho, and O. J. Pozo, "Critical review of the application of liquid chromatography/mass spectrometry to the determination of pesticide residues in biological samples," Analytical and Bioanalytical Chemistry, vol. 382, pp. 934-946, 2005.

[5] G. Qian, L. Wang, Y. Wu et al., "A monoclonal antibodybased sensitive enzyme-linked immunosorbent assay (ELISA) for the analysis of the organophosphorous pesticides chlorpyrifos-methyl in real samples," Food Chemistry, vol. 117, no. 2, pp. 364-370, 2009.

[6] D. Chen, C. Chen, and D. Du, "Detection of organophosphate pesticide using polyaniline and carbon nanotubes composite based on acetylcholinesterase inhibition," Journal of Nanoscience and Nanotechnology, vol. 10, no. 9, pp. 5662-5666, 2010.

[7] W. Zhao, P.-Y. Ge, J.-J. Xu, and H.-Y. Chen, "Selective detection of hypertoxic organophosphates pesticides via PDMS composite based acetylcholinesterase-inhibition biosensor," Environmental Science \& Technology, vol. 43, no. 17, pp. 6724-6729, 2009.

[8] S. Nouanthavong, D. Nacapricha, C. S. Henry, and Y. Sameenoi, "Pesticide analysis using nanoceria-coated paper-based devices as a detection platform," The Analyst, vol. 141, no. 5, pp. 1837-1846, 2016.

[9] J. Gupta, Q. Zhao, G. Wang, X. Kang, and X. Guan, "Simultaneous detection of CMPA and PMPA, hydrolytes of soman and cyclosarin nerve agents, by nanopore analysis," Sensors and Actuators B: Chemical, vol. 176, pp. 625-631, 2013.

[10] N. Prabhakar, H. Thakur, A. Bharti, and N. Kaur, "Chitosaniron oxide nanocomposite based electrochemical aptasensor for determination of malathion," Analytica Chimica Acta, vol. 939, pp. 108-116, 2016.

[11] W. Bai, C. Zhu, J. Liu, M. Yan, S. Yang, and A. Chen, "Gold nanoparticle-based colorimetric aptasensor for rapid detection of six organophosphorous pesticides," Environmental Toxicology and Chemistry, vol. 34, no. 10, pp. 2244-2249, 2015.

[12] T. Qin, Y. Tianxi, Q. Yanqi et al., "In situ colorimetric detection of glyphosate on plant tissues using cysteaminemodified gold nanoparticles," The Analyst, vol. 144, pp. 2017-2022, 2019. 
[13] I. S. C. Sulaiman, B. W. Chieng, M. J. Osman et al., "A review on colorimetric methods for determination of organophosphate pesticides using gold and silver nanoparticles," Microchimica Acta, vol. 187, no. 2, pp. 1-22, 2020.

[14] V. Kumar, N. Upadhyay, V. Kumar, and S. Sharma, “A review on sample preparation and chromatographic determination of acephate and methamidophos in different samples," Arabian Journal of Chemistry, vol. 8, no. 5, pp. 624-631, 2015.

[15] J. V. Peter, T. Sudarsan, and J. Moran, "Clinical features of organophosphate poisoning: a review of different classification systems and approaches," Indian Journal of Critical Care Medicine, vol. 18, no. 11, pp. 735-745, 2014.

[16] M. C. Dumlao, L. E. Jeffress, J. J. Gooding, and W. A. Donald, "Solid-phase microextraction low temperature plasma mass spectrometry for the direct and rapid analysis of chemical warfare simulants in complex mixtures," The Analyst, vol. 141, no. 12 , pp. 3714-3721, 2016.

[17] M. Kumar and N. Upadhay, "2665 chemical shifts and coupling constants for C13H21O4P," Chemical Shifts and Coupling Constants for Phosphorus-31, vol. 4, no. 6, p. 2674, 2013.

[18] A. T. Farag, M. H. Eweidah, and A. M. El-okazy, "Reproductive toxicology of acephate in male mice," Reproductive Toxicology, vol. 14, no. 5, pp. 457-462, 2000.

[19] D. Spassova, T. White, and A. K. Singh, "Acute effects of acephate and methamidophos on acetylcholinesterase activity, endocrine system and amino acid concentrations in rats," Comparative Biochemistry and Physiology Part C: Pharmacology, Toxicology and Endocrinology, vol. 126, no. 1, pp. 79-89, 2000.

[20] E. Dyguda-Kazimierowicz, S. Roszak, and W. A. Sokalski, "Alkaline hydrolysis of organophosphorus pesticides: the dependence of the reaction mechanism on the incoming group conformation," The Journal of Physical Chemistry B, vol. 118, no. 26, pp. 7277-7289, 2014.

[21] M.-C. Daniel and D. Astruc, "Gold nanoparticles: assembly, supramolecular chemistry, quantum-size-related properties, and applications toward biology, catalysis, and nanotechnology," Chemical Reviews, vol. 104, no. 1, pp. 293-346, 2004.

[22] S. Menon, S. Rajeshkumar, and S. Venkat Kumar, "A review on biogenic synthesis of gold nanoparticles, characterization, and its applications," Resource-Efficient Technologies, vol. 3, no. 4, pp. 516-527, 2017.

[23] M. Sengani, A. M. Grumezescu, and V. D. Rajeswari, "Recent trends and methodologies in gold nanoparticle synthesis-a prospective review on drug delivery aspect," OpenNano, vol. 2, pp. 37-46, 2017.

[24] V. A. Dhumale, R. K. Gangwar, S. S. Datar, and R. B. Sharma, "Reversible aggregation control of polyvinylpyrrolidone capped gold nanoparticles as a function of $\mathrm{pH}$," Materials Express, vol. 2, no. 4, pp. 311-318, 2012.

[25] K. Wagers, T. Chui, and S. Adem, "Effect of pH on the stability of gold nanoparticles and their application for melamine detection in infant formula," IOSR Journal of Applied Chemistry, vol. 7, no. 8, pp. 15-20, 2014.

[26] E. Priyadarshini and N. Pradhan, "Metal-induced aggregation of valine capped gold nanoparticles: an efficient and rapid approach for colorimetric detection of $\mathrm{Pb} 2+$ ions," Scientific Reports, vol. 7, no. 1, pp. 1-8, 2017.

[27] V. K. T. Ngo, D. G. Nguyen, P. H. Trong, and Q. V. Lam, “A low cost technique for synthesis of gold nanoparticles using microwave heating and its application in signal amplification for detecting Escherichia Coli O157: H7 bacteria," Advances in Natural Sciences: Nanoscience and Nanotechnology, vol. 7, no. 3, ArticleID 35016, 2016, http://stacks.iop.org/2043-6262/ $7 / \mathrm{i}=3 / \mathrm{a}=035016$.
[28] A. K. Augustine, V. P. N. Nampoori, and M. Kailasnath, "Rapid synthesize of gold nanoparticles by microwave irradiation method and its application as an optical limiting material," Optik, vol. 125, no. 22, pp. 6696-6699, 2014.

[29] R. Bala, R. K. Sharma, and N. Wangoo, "Development of gold nanoparticles-based aptasensor for the colorimetric detection of organophosphorus pesticide phorate," Analytical and Bioanalytical Chemistry, vol. 408, no. 1, pp. 333-338, 2015.

[30] J. Polte, T. T. Ahner, F. Delissen et al., "Mechanism of gold nanoparticle formation in the classical citrate synthesis method derived from coupled in situ XANES and SAXS evaluation," Journal of the American Chemical Society, vol. 132, no. 4, pp. 1296-1301, 2010.

[31] K. M. A. El-Nour, E. T. A. Salam, H. M. Soliman, and A. S. Orabi, "Gold nanoparticles as a direct and rapid sensor for sensitive analytical detection of biogenic amines," Nanoscale Research Letters, vol. 12, no. 1, 2017.

[32] L. Gong, B. Du, L. Pan et al., "Colorimetric aggregation assay for arsenic (III) using gold nanoparticles," Microchimica Acta, vol. 184, no. 4, pp. 1185-1190, 2017.

[33] H. Aldewachi, N. Woodroofe, and P. Gardiner, "Study of the stability of functionalized gold nanoparticles for the colorimetric detection of dipeptidyl peptidase IV," Applied Sciences, vol. 8, no. 12, p. 2589, 2018.

[34] O. Pluchery, H. Remita, and D. Schaming, "Demonstrative experiments about gold nanoparticles and nanofilms: an introduction to nanoscience," Gold Bulletin, vol. 46, no. 4, pp. 319-327, 2013.

[35] W. P. Pradeep and P. J. Ashok, "A review on gold nanoprticles synthesis and characterization," Universal Journal of Pharmaceutical Research, vol. 2, no. 4, pp. 65-69, 2017.

[36] G. Jiang, L. Wang, and W. Chen, "Studies on the preparation and characterization of gold nanoparticles protected by dendrons," Materials Letters, vol. 61, no. 1, pp. 278-283, 2007.

[37] R. West, Y. Wang, and T. Goodson, "Nonlinear absorption properties in novel gold nanostructured topologies," The Journal of Physical Chemistry B, vol. 107, no. 15, pp. 34193426, 2003.

[38] M. K. Corbierre, N. S. Cameron, and R. B. Lennox, "Polymerstabilized gold nanoparticles with high grafting densities," Langmuir, vol. 20, no. 7, pp. 2867-2873, 2004.

[39] S. Link and M. A. El-Sayed, "Spectral properties and relaxation dynamics of surface plasmon electronic oscillations in gold and silver nanodots and nanorods," The Journal of Physical Chemistry B, vol. 103, no. 40, pp. 8410-8426, 1999.

[40] Z. Lin, X. Wang, J. Liu et al., "On the role of localized surface plasmon resonance in $\mathrm{UV}$-vis light irradiated $\mathrm{Au} / \mathrm{TiO} 2$ photocatalysis system: pros and cons," Nanoscale, vol. 7, no. 9, pp. 4114-4123, 2015.

[41] N. Rajib, L. Lisha, D. Joydip, J. Varsha, and K. P. Santanu, "Gold Nanoparticle mediated signal amplification of liquid crystal biosensor for dopamine," The Analyst, vol. 144, pp. 1110-1114, 2019.

[42] O. Varnavski, R. G. Ispasoiu, L. Balogh, D. Tomalia, and T. Goodson, "Ultrafast time-resolved photoluminescence from novel metal-dendrimer nanocomposites," The Journal of Chemical Physics, vol. 114, no. 5, pp. 1962-1965, 2001.

[43] Z. Yuan, C.-C. Hu, H.-T. Chang, and C. Lu, "Gold nanoparticles as sensitive optical probes," The Analyst, vol. 141, no. 5, pp. 1611-1626, 2016.

[44] T. A. Taton, G. Lu, and C. A. Mirkin, “Two-color labeling of oligonucleotide arrays via size-selective scattering of nanoparticle probes," Journal of the American Chemical Society, vol. 123, no. 21, pp. 5164-5165, 2001. 
[45] X. Liu, M. Atwater, J. Wang, and Q. Huo, "Extinction coefficient of gold nanoparticles with different sizes and different capping ligands," Colloids and Surfaces B: Biointerfaces, vol. 58, no. 1, pp. 3-7, 2007.

[46] A. K. Singh, T. White, D. Spassova, and Y. Jiang, "Physicochemical, molecular-orbital and electronic properties of acephate and methamidophos," Comparative Biochemistry and Physiology Part C: Pharmacology, Toxicology and Endocrinology, vol. 119, no. 1, pp. 107-117, 1998.

[47] R. Bala, M. Kumar, K. Bansal, R. K. Sharma, and N. Wangoo, "Ultrasensitive aptamer biosensor for malathion detection based on cationic polymer and gold nanoparticles," Biosensors and Bioelectronics, vol. 85, pp. 445-449, 2016.

[48] J. R. Durig, D. W. Wertz, B. R. Mitchell, F. Block, and J. M. Greene, "Vibrational spectra of organophosphorus compounds. III. Infrared and Raman spectra of dimethylphosphinothioic chloride, dimethylphosphinothioic bromide, and dimethylphosphinic chloride," The Journal of Physical Chemistry, vol. 71, no. 12, pp. 3815-3823, 1967.

[49] R. R. Shagidullin and I. P. Lipatova, "IR spectra and structures of certain organothiophosphorus compounds," Bulletin of the Academy of Sciences of the USSR Division of Chemical Science, vol. 20, no. 5, pp. 940-942, 1971.

[50] T. Eleršek and M. Filipi, "Organophosphorus pesticidesmechanisms of their toxicity," Pesticides-Impacts Pesticides Exposure, pp. 243-260, 2011.

[51] S. Mazurek, A. Mucciolo, B. M. Humbel, and C. Nawrath, "Transmission Fourier transform infrared microspectroscopy allows simultaneous assessment of cutin and cell-wall polysaccharides of Arabidopsis petals," The Plant Journal, vol. 74, no. 5, pp. 880-891, 2013.

[52] P. Duenchay, K. Kaewjua, O. Chailapakul, and W. Siangproh, "Application of modifier-free gold nanoparticle colorimetric sensing for rapid screening and detection of vitamin B1," New Journal of Chemistry, vol. 44, no. 22, pp. 9223-9229, 2020.

[53] H. Niu, S. Wang, Z. Zhou, Y. Ma, X. Ma, and Y. Cai, "Sensitive colorimetric visualization of perfluorinated compounds using poly (ethylene glycol) and perfluorinated thiols modified gold nanoparticles," Analytical Chemistry, vol. 86, no. 9, pp. 4170-4177, 2014.

[54] X. Lu, L. Tao, D. Song, Y. Li, and F. Gao, "Bimetallic Pd@Au nanorods based ultrasensitive acetylcholinesterase biosensor for determination of organophosphate pesticides," Sensors and Actuators B: Chemical, vol. 255, no. 3, pp. 2575-2581, 2018.

[55] S. Diamai, W. Warjri, D. Saha, and D. P. S. Negi, "Sensitive determination of 6-mercaptopurine based on the aggregation of phenylalanine-capped gold nanoparticles," Colloids and Surfaces A: Physicochemical and Engineering Aspects, vol. 538, pp. 593-599, 2018.

[56] W. Chungchai, M. Amatatongchai, R. Meelapsom, K. Seebunrueng, S. Suparsorn, and P. Jarujamrus, "Development of a novel three-dimensional microfluidic paperbased analytical device (3D- $\mu \mathrm{PAD}$ ) for chlorpyrifos detection using graphene quantum-dot capped gold nanocomposite for colorimetric assay," International Journal of Environmental Analytical Chemistry, vol. 100, no. 10, pp. 1160-1178, 2019.

[57] S. Teepoo, P. Chumsaeng, K. Palasak, N. Bousod, N. Mhadbamrung, and P. Sae-lim, "Unmodified gold nanoparticles as a simple colorimetric probe for ramoplanin detection," Talanta, vol. 117, pp. 518-522, 2013.

[58] J. Du, B. Zhu, X. Peng, and X. Chen, "Optical reading of contaminants in aqueous media based on gold nanoparticles," Small, vol. 10, no. 17, pp. 3461-3479, 2014. 